\title{
Intussusception caused by an inverted colonic diverticulum: a case report
}

\author{
Bei Zhang ${ }^{1}$, Jiping Wang ${ }^{1}$, Xiaoguang $\mathrm{Li}^{2}$, Zhuo Wang ${ }^{1}$, Yangjiao Zhang ${ }^{1}$ and Hao Yang ${ }^{2^{*}}$
}

\begin{abstract}
Background: Intussusception is an unusual disorder among the complications of diverticula in adults. This study aimed to report intussusception due to an inverted colonic diverticulum. Such a large inverted colonic diverticulum has rarely been reported.

Case presentation: A 62-year-old Chinese woman presented to the First Hospital of Jilin University with abdominal pain, vomiting, and bloody stool. Preoperative computed tomography imaging indicated intussusception. The intraoperative diagnosis was consistent with postoperative pathology. Our patient was diagnosed as having an inverted colonic diverticulum near the ileocecal valve with intussusception and intestinal necrosis.

Conclusion: Although inverted colonic diverticulum is extremely rare, it should also be considered among the causative factors of intussusception.
\end{abstract}

Keywords: Emergency operation, Intussusception, Inverted colonic diverticulum

\section{Background}

Colonic diverticulum seldom has clinical symptoms [1]. When colonic diverticulum is associated with complications, surgical treatment may be considered [2]. Intussusception is one of the emergency situations. Among the most reported complications, intussusception was described occasionally, but an inverted colonic diverticulum (ICD) as large as the one reported in the present study has rarely been described. The correct preoperative diagnosis of intussusception due to ICD has rarely been made [3]. This study aimed to present the case of an ICD complicated by ileocolonic intussusception in a Chinese elderly woman successfully treated surgically.

\section{Case presentation}

A 62-year-old Chinese woman presented to the First Hospital of Jilin University with complaints of abdominal pain, vomiting, and bloody stool for 24 hours. On admission, her general condition was good. Her temperature was $37.1{ }^{\circ} \mathrm{C}$, respiratory rate was 18 times per minute, and heart rate was 80 beats per minute. She did not have cutaneous or scleral icterus. No superficial

\footnotetext{
* Correspondence: 15104311639@139.com

2Department of Gastrointestinal Surgery, First Hospital of Jilin University,

No.71, Xinmin Street, Changchun 130021, China

Full list of author information is available at the end of the article
}

tumescent lymph nodes were observed. A physical examination showed distended abdomen with no stomach outline, peristalsis, and varicose veins. Abdominal breathing was slightly limited. Abdominal tenderness could be detected in her right abdomen accompanied by rebound tenderness and muscle tension. A palpable mass could be detected in her right lower abdomen. Liver, spleen, and gallbladder could not be touched below the costal arch. Murphy's sign and shifting dullness were negative. Bowel sound was found to be approximately 7 beats per minute with gurgling. A neurological physical examination had no significant findings. A physical examination of her heart and chest was normal. She was a housewife in a small city with no special family history. She had a history of hypertension for 10 years, and the use of captopril helped maintain a satisfactory level of blood pressure. She denied a history of hepatitis, tuberculosis, and diabetes. Also, no history of drug allergy, surgeries, tobacco smoking, and longterm alcohol consumption was reported. The results of complete blood count, liver function, and blood biochemical indexes are shown in Tables 1 and 2. The results of coagulation markers of hepatitis B virus, hepatitis $\mathrm{C}$ virus, syphilis, and human immunodeficiency virus were found to be negative. Abdominal computed tomography $(\mathrm{CT})$ was performed, which showed some 
Table 1 Complete blood count before and after surgery

\begin{tabular}{lllll}
\hline Items & Unit & Before surgery & First day after surgery & Second day after surgery \\
\hline Red blood cell (RBC) & $\times 10^{12} / \mathrm{L}$ & 4.65 & 3.96 & 3.80 \\
Hemoglobin (HGB) & $\mathrm{g} / \mathrm{L}$ & 140 & 118 & 117 \\
Hematocrit (HCT) & $\mathrm{L} / \mathrm{L}$ & 0.411 & 0.353 & 0.352 \\
Mean corpuscular volume (MCV) & $\mathrm{fL}$ & 88.4 & 89.1 & 92.6 \\
Mean corpuscular hemoglobin (MCH) & $\mathrm{pg}$ & 30.1 & 29.8 & 30.8 \\
Mean corpuscular hemoglobin concentration (MCHC) & $\mathrm{g} / \mathrm{L}$ & 341 & 334 & 332 \\
Platelet (PLT) & $\times 10^{9} / \mathrm{L}$ & 216 & 196 & 167 \\
White blood cell (WBC) & $\times 10^{9} / \mathrm{L}$ & 9.40 & 17.21 & 10.62 \\
Neutrophil count (NE) & $\times 10^{9} / \mathrm{L}$ & 8.12 & 14.45 & 8.98 \\
Lymphocyte count (LY) & $\times 10^{9} / \mathrm{L}$ & 0.95 & 1.57 & 0.79 \\
Monocyte count (MO) & $\times 10^{9} / \mathrm{L}$ & 0.32 & 1.15 & 0.82 \\
Eosinophil count (EO) & $\times 10^{9} / \mathrm{L}$ & 0.01 & 0.04 & 0.01 \\
Neutrophil percentage (NE\%) & & 0.86 & 0.84 & 0.85 \\
Lymphocyte percentage (LY\%) & & 0.10 & 0.09 & 0.07 \\
Monocyte percentage (MO\%) & & 0.03 & 0.07 & 0.08 \\
Eosinophil percentage (EO\%) & & 0.00 & 0.00 & \\
\hline
\end{tabular}

intestinal canals and mesentery entering into the right colon. The CT scan showed a target sign suggesting intussusception in her right abdomen (Fig. 1a, b).

Surgical exploration revealed that the ICD entered her ascending colon with edema (Figs. 1c, d and 2). The diverticulum was suspected of blood supply deficiency. No obvious abnormalities were found in the remaining colon and rectum. Intussusception was diagnosed during

Table 2 Blood biochemical examination

\begin{tabular}{llll}
\hline Items & Unit & $\begin{array}{l}\text { Before } \\
\text { surgery }\end{array}$ & $\begin{array}{l}\text { First day after } \\
\text { surgery }\end{array}$ \\
\hline Alanine aminotransferase (ALT) & $\mathrm{U} / \mathrm{L}$ & 17.1 & \\
Alkaline phosphatase (ALP) & $\mathrm{U} / \mathrm{L}$ & 51.7 & \\
Total protein (TP) & $\mathrm{g} / \mathrm{L}$ & 67.7 & \\
Albumin (ALB) & $\mathrm{g} / \mathrm{L}$ & 41.9 & \\
Globulin (GLO) & $\mathrm{g} / \mathrm{L}$ & 25.8 & \\
Albumin/Globulin (A/G) & & 1.62 & \\
Total bilirubin in serum (TBIL) & $\mu \mathrm{mol} / \mathrm{L}$ & 12.4 & \\
Direct bilirubin in serum (DBIL) & $\mu \mathrm{mol} / \mathrm{L}$ & 2.1 & \\
Indirect bilirubin in serum (IBIL) & $\mu \mathrm{mol} / \mathrm{L}$ & 10.3 & \\
Blood urea nitrogen (BUN) & $\mathrm{mmol} / \mathrm{L}$ & & \\
Serum creatinine (Cr) & $\mu \mathrm{mol} / \mathrm{L}$ & 47.7 & 52.0 \\
Urea & $\mathrm{mmol} / \mathrm{L}$ & 4.90 & 5.21 \\
$\mathrm{~K}^{+}$ & $\mathrm{mmol} / \mathrm{L}$ & 3.97 & 3.64 \\
$\mathrm{Na}^{+}$ & $\mathrm{mmol} / \mathrm{L}$ & 134.9 & 131.6 \\
$\mathrm{Cl}^{-}$ & $\mathrm{mmol} / \mathrm{L}$ & 100.1 & 99.5 \\
$\mathrm{Ca}^{2+}$ & $\mathrm{mmol} / \mathrm{L}$ & 2.16 & 1.93 \\
\hline
\end{tabular}
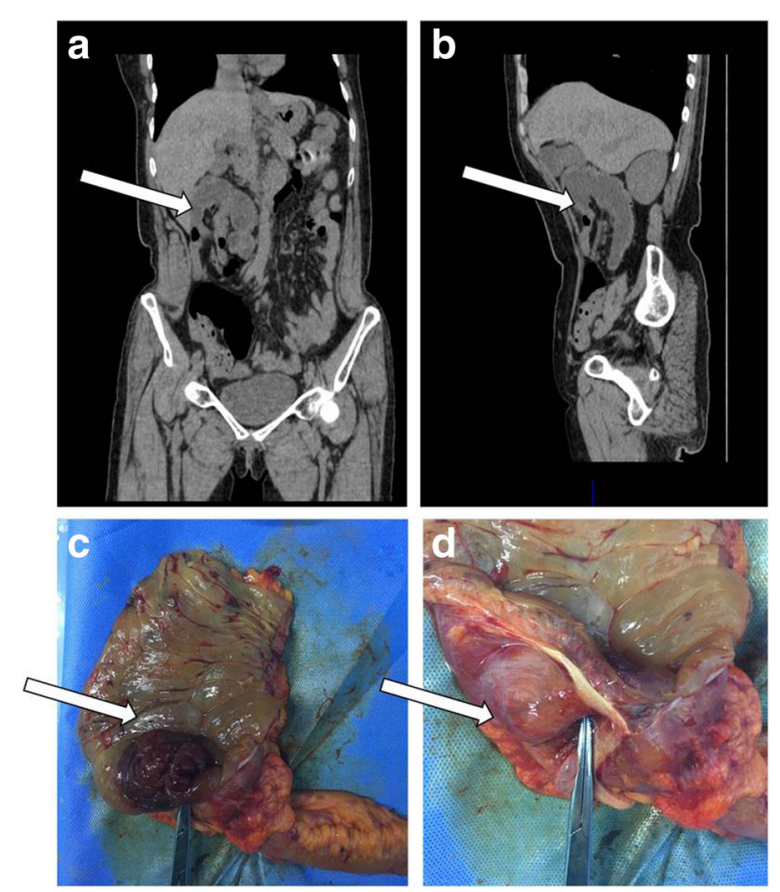

Fig. 1 Computed tomography imaging and gross sample. $\mathbf{a}$ and $\mathbf{b}$ A computed tomography scan showed the target sign (white arrow) in the right abdomen. Colonic diverticulum entered the right colon. c and $\mathbf{d}$ Gross specimen showed the entry of colonic diverticulum (white arrow) into the ascending colon 


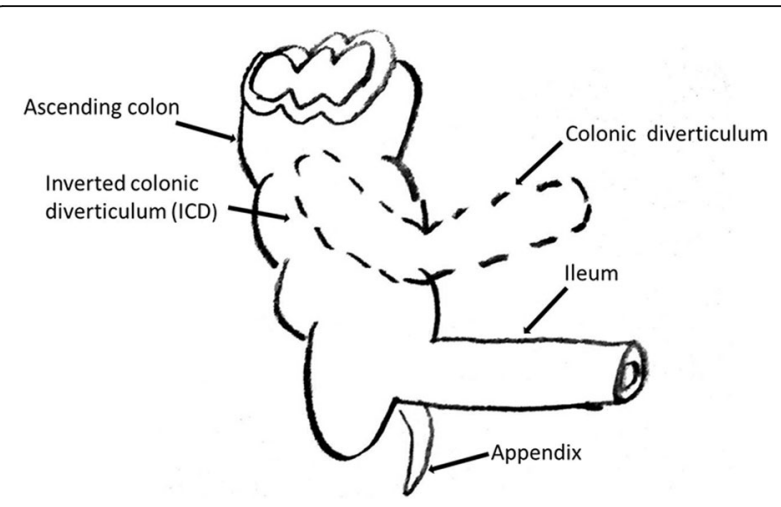

Fig. 2 Schematic image of the intussusception caused by an inverted colonic diverticulum. ICD inverted colonic diverticulum

the operation. Right hemicolectomy was performed under laparoscopy.

A histopathological examination showed that the ICD was on the side of ascending colon, causing ileocolonic intussusception with intestinal necrosis (Fig. 3). The diameter was approximately $3.8 \mathrm{~cm}$.

Cefmenoxime hydrochloride injection (2 g) was used before and after the surgery to prevent infection. Our patient quickly recovered and was discharged 7 days after the surgery without any complications. She had a telephonic follow-up 10 months after discharge from our hospital. She had no apparent symptoms after the surgery. Serological and imaging examinations were performed in a local hospital, and the results were negative.

\section{Discussion}

Colonic diverticular disease is a common condition. However, it has become increasingly difficult to ignore a

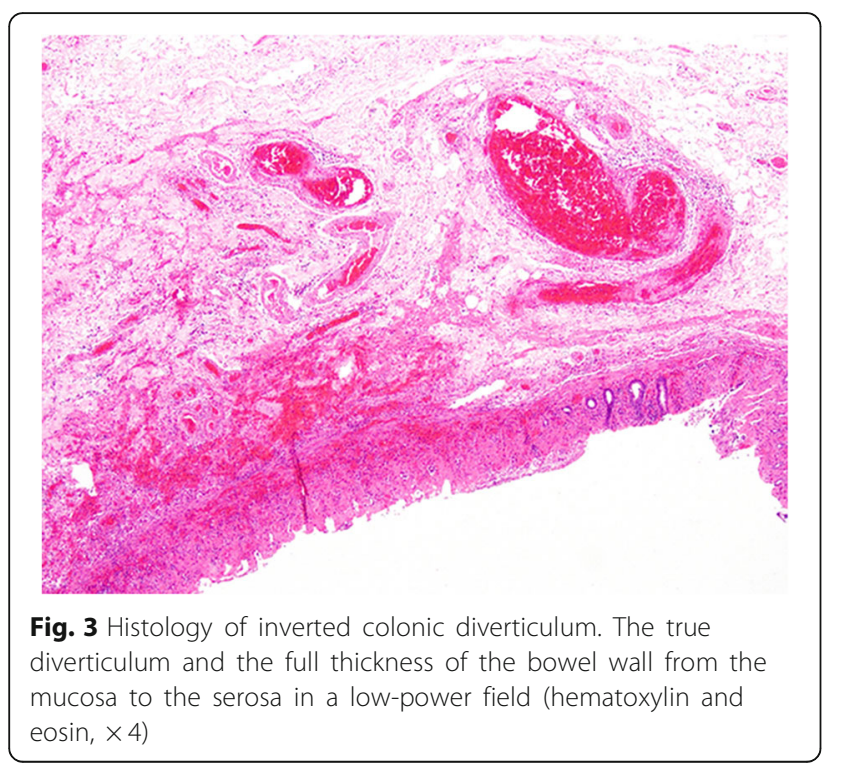

singular relatively large diverticulum. A previous study reported giant ascending colonic diverticulum with intussusception [3]. The diameter of the diverticulum described in that report was larger than $4 \mathrm{~cm}$, but the diverticulum in the present study was not as large as that giant colonic diverticulum. In the present study, intussusception was caused by an ICD with a diameter of $3.8 \mathrm{~cm}$.

Intussusception refers to the insertion of an intestinal tube into the contiguous lumen, usually leading to intestinal obstruction and ischemia [4]. Intussusception in adults accounts for $1-3 \%$ of intestinal obstruction in adults [5]. The etiology of more than $90 \%$ of adult intussusceptions has been reported [6]. However, the preoperative diagnosis of adult intussusception still remains difficult. Abdominal CT is usually used in the preoperative evaluation. Surgery is the recommended treatment.

ICD is rare. The incidence rate of ICD is approximately $0.7 \%$ [7]. The smaller ICD tends to be indistinguishable from colonic polyps. Endoscopic biopsy or polypectomy can be dangerous in such a situation [7]. The water jet deformation sign is thought to be a safer and more reliable method compared with biopsy forceps and air insufflation [8]. The differential diagnosis includes cecal volvulus, a duplication cyst or giant Meckel diverticulum, and pneumatosis cystoides intestinalis.

The lesion in the patient in this study was unusual. It occurred in the colon close to the ileocecal valve. The diameter was $3.8 \mathrm{~cm}$, not larger than $4.0 \mathrm{~cm}$, and the lesion was not located in the sigmoid colon. It could not be defined as a giant colonic diverticulum because the diameter of a giant colonic diverticulum needs to be larger than $4 \mathrm{~cm}$, more often occurring in the sigmoid colon [9]. The mechanism of the formation of large diverticula is not fully known. One possibility is the ballvalve mechanism. A narrow passage between the normal bowel and the diverticulum makes the diverticulum larger [10]. Although the size of the lesion reported in this study did not reach $4.0 \mathrm{~cm}$, the evolutionary process of a giant colonic diverticulum could not be excluded. Any intestinal condition that changes the normal pattern of peristalsis increases the risk of intussusception. Colonic diverticulum as a rare cause of adult intussusception was shown in this study. A previous study retrospectively reviewed 16 years of data from patients with intussusception and found that $77.3 \%$ of cases were related to a tumor, $73.5 \%$ of which were malignant. Among these, $11.3 \%$ occurred in a postoperative setting and $11.3 \%$ were idiopathic [11]. The intussusception due to ICD in the present case is a rare event in adult patients. Although the exact mechanism of invagination is unknown in this case, it is speculated that the existence of colonic diverticulum caused abnormal peristalsis of the intestines. Furthermore, the diameter of the diverticulum was relatively large in size. 
A previous study reported intussusception caused by a giant colonic diverticulum. A laparoscopic right hemicolectomy was performed for one-stage treatment [3]. Roch et al. reported that laparoscopic atypical colon wedge resection was safely performed, and it might be considered an alternative for extended resections of giant diverticula [12].

\section{Conclusion}

Although such a large ICD is extremely rare, it should also be considered among the causative factors of intussusception.

\section{Acknowledgements}

Not applicable.

\section{Funding}

Not applicable.

\section{Availability of data and materials}

Not applicable.

\section{Authors' contributions}

BZ was a major contributor in writing the manuscript and interpreting the $\mathrm{CT}$ imaging. $\mathrm{HY}$ recorded intraoperative condition and performed the physical examination. JW and XL helped modify the manuscript. All authors read and approved the final manuscript.

\section{Ethics approval and consent to participate}

Ethical approval was obtained from the First Hospital of Jilin University Research Ethics Committee. The patient gave written informed consent to participate in this study.

\section{Consent for publication}

Written informed consent was obtained from the patient for publication of this report and any accompanying images. A copy of the written consent is available for review by the Editor-in-Chief of this journal.

\section{Competing interests}

The authors declare that they have no competing interests.

\section{Publisher's Note}

Springer Nature remains neutral with regard to jurisdictional claims in published maps and institutional affiliations.

\section{Author details}

'Department of Radiology, First Hospital of Jilin University, Changchun, China. ${ }^{2}$ Department of Gastrointestinal Surgery, First Hospital of Jilin University, No.71, Xinmin Street, Changchun 130021, China.

Received: 20 September 2017 Accepted: 9 March 2018

Published online: 27 April 2018

\section{References}

1. Del Pozo AC, Bartolotta V, Capitano S, Fusco MD, Chiodi L, Boccoli G. A gas-filled abdominal cyst in an elderly woman: A giant colonic diverticulum case report. Int I Surg Case Rep. 2016;24:104-7.

2. Zeina AR, Mahamid A, Nachtigal A, Ashkenazi I, Shapira-Rootman M. Giant colonic diverticulum: radiographic and MDCT characteristics. Insights Imaging. 2015;6:659-64.

3. Kim HJ, Kim JH, Moon Ol, Kim KJ. Giant ascending colonic diverticulum presenting with intussusception. Ann Coloproctol. 2013;29:209-12.

4. Catalano O. Transient small bowel intussusception: $C T$ findings in adults. Br J Radiol. 1997:70:805-8.

5. Maghrebi H, Makni A, Rhaiem R, et al. Adult intussusceptions: Clinical presentation, diagnosis and therapeutic management. Int J Surg Case Rep. 2017;33:163-6.
6. Marinis A, Yiallourou A, Samanides L, et al. Intussusception of the bowel in adults: a review. World J Gastroenterol. 2009:15:407-11.

7. Adioui T, Seddik H. Inverted colonic diverticulum. Ann Gastroenterol. 2014;27:411.

8. Cappell MS. The water jet deformation sign: a novel provocative colonoscopic maneuver to help diagnose an inverted colonic diverticulum. South Med J. 2009:102:295-8.

9. Di Grezia G, Gatta G, Rella R, et al. Abdominal Hernias, Giant Colon Diverticulum, GIST, Intestinal Pneumatosis, Colon Ischemia, Cold Intussusception, Gallstone lleus, and Foreign Bodies: Our Experience and Literature Review of Incidental Gastrointestinal MDCT Findings. Biomed Res Int. 2017;2017:5716835

10. de Oliveira NC, Welch JP. Giant diverticula of the colon: a clinical assessment. Am J Gastroenterol. 1997;92:1092-6.

11. Honjo H, Mike M, Kusanagi H, Kano N. Adult intussusception: a retrospective review. World J Surg. 2015;39:134-8.

12. Roch PJ, Friedrich $T$, Bönninghoff $R$, et al. Laparoscopic resection of a giant colon diverticulum: Case report and review of the literature. Chirurg. 2017:88:682-6.
Submit your next manuscript to BioMed Central and we will help you at every step:

- We accept pre-submission inquiries

- Our selector tool helps you to find the most relevant journal

- We provide round the clock customer support

- Convenient online submission

- Thorough peer review

- Inclusion in PubMed and all major indexing services

- Maximum visibility for your research

Submit your manuscript at www.biomedcentral.com/submit
) Biomed Central 